\title{
An Interesting Case of Isolated Renal Stab Injury
}

VINAYAK GORAKHNATH WAGASKAR, VIDYASAGAR HANSRAJ BAHETI,

AJAYKUMAR R GAJENGI, SUJATA KIRAN PATWARDHAN

\section{ABSTRACT}

Isolated renal penetrating injury requiring exploration is rare. Kidney is retroperitoneal organ with strong muscular and rib cage support. Added to this Gerota's fascia prevent direct injury to renal parenchyma. Here we have presented an interesting case of renal stab injury in young man who had completely divided kidney due to knife. Patient managed with nephrectomy. He fared well the procedure as well as post-operative recovery. We discussed this case with literature review but isolated renal stab injury was not found. We also presented elegant images of this case.

Keywords: Gerota's fascia, Kidney, Nephrectomy, Penetrating injury

\section{CASE REPORT}

A 30 years old male patient presented to the casualty with history of homicidal stab injury with a knife in the left flank 6 hours ago. Patient was initially taken to a private hospital where he was stabilized and a Contrast Enhanced Computed Tomography (CECT) scan was done and then referred to our Centre. On arrival patient had the weapon of assault in situ in the left flank, with only the handle of the knife protruding out [Table/Fig-1]. On examination he was conscious and oriented, pale but vitally stable with pulse of 100 /minute and $\mathrm{BP}$ of $130 / 90 \mathrm{mmHg}$ Abdomen had slight amount of guarding and rigidity. There was gross hematuria in the urine bag. His Hemoglobin was $7.8 \mathrm{gm} / \mathrm{dl}$, and renal function tests were normal. CECT scan showed penetrating injury with a serrated broad knife to the left kidney with suspicious involvement of left pleura [Table/Fig-2,3].

Decision to do exploratory laparotomy was taken in conjunction with the general surgeons. Patient was explored in partial flank position, haemoperitonium cleared and pointed end of the knife seen penetrating the mesentery [Table/Fig-4].

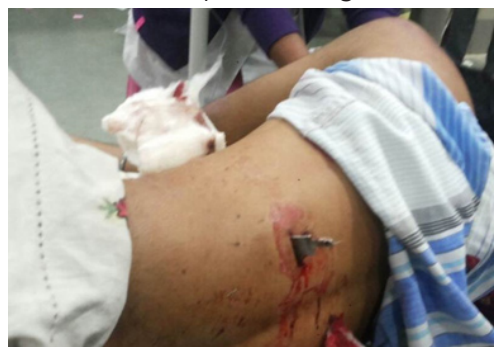

[Table/Fig-1]: Presentation of the patient to the casualty with stab injury to left flank and handle of knife protruding out. [Table/Fig-2]: Plain images of CT scan showing knife and its location and direction [Table/Fig-3]: Coronal images of CECT scan showing knife completely bivalving left kidney. Vascular injury to left renal structures not appreciated.
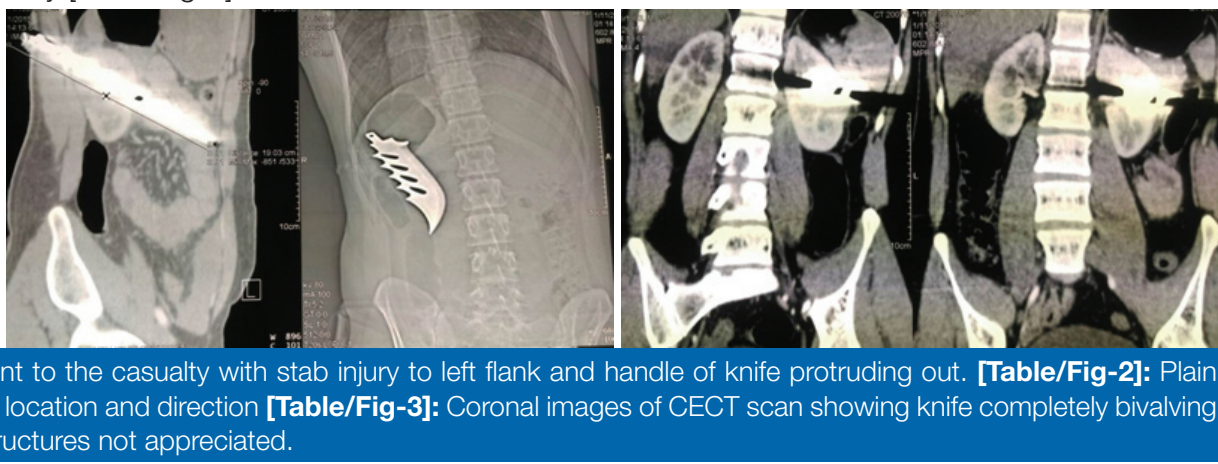

Retroperitonium was entered after extending the incision to flank and kidney approached. Lacerated kidney found with breach of pelvis with significant ongoing blood loss. Renal pedicle was clamped and total nephrectomy was done. Small rent in the small bowel was primarily repaired and pleura closed with Intercostal Drainage (ICD) tube inserted. No other significant injury was found on further exploration of other abdominal organs. Closure of the abdominal and flank wound was done after insertion of two abdominal drains. [Table/ Fig-5] shows left nephrectomy specimen with position of knife observed at exploration. Patient withstood the procedure well. He was extubated on the table and shifted to the surgical intensive care unit. Postoperatively patient fared well, drains removed on day 5 and ICD on day 6 and patient discharged on day 10.

\section{DISCUSSION}

The most frequently injured urologic organ is the kidney is with $70 \%$ to $80 \%$ being a consequence of blunt trauma [1]. Kidney is a retroperitoneal organ surrounded by strong muscular 


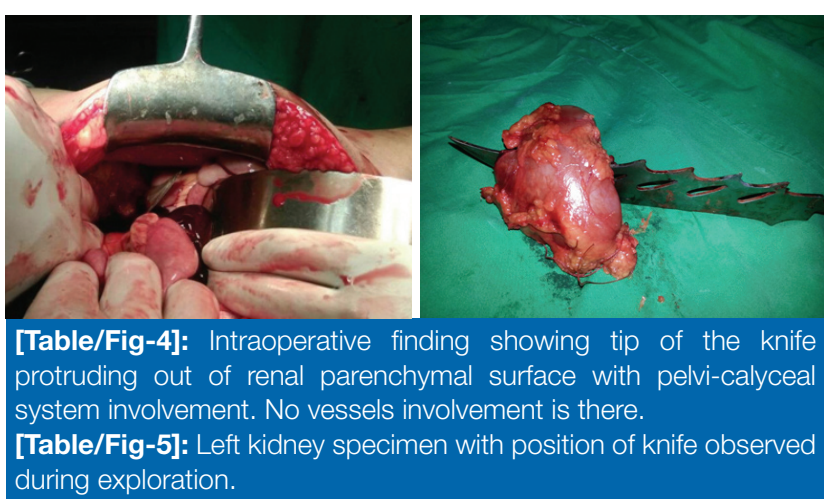

support and enclosed in Gerota's fascia [2]. Isolated renal stab injury is not common as other penetrating injuries to abdomen. Velmahos et al., [3] prospectively studied 79 patients with penetrating wounds to the flank which involved the urinary tract. They have managed five of these (6 per cent) patients non-operatively and sixteen patients (20 per cent) underwent abdominal but not renal exploration. They concluded that, in cases of stable renal hematomas invasion of Gerota's fascia may be spared.

Peterson et al., [4] described 60 patients with penetrating renal injuries, of which exploration is required in 42 cases (70\%). Excluding unnecessary renal explorations only 27 cases (45\%) would have required renal exploration. Our patient was hemodynamically stable but had gross hematuria and that to knife in situ.

In a more recent series, Eastham et al., [5] found 43 injuries on imaging out of 244 patients with renal-proximity stab wounds. Eighteen patients with minor injuries were managed non-operatively, and 9 patients with vascular injuries were managed successfully with trans catheter embolization. All patients with Grades III or IV injuries were explored. They concluded that most renal injuries, when accurately staged, can be safely managed non-operatively.

Atala et al., [6] described 75 patients of renal exploration for either penetrating orblunt renal injury. They concluded thatnephrectomy rate was depend on the degree of injury rather than on the type of renal vascular control obtained.

Our patient had isolated left renal stab injury without major vascular injury. He underwent nephrectomy and withstood the procedure well.

\section{CONCLUSION}

Though isolated renal stab injury is rare careful selection of case for exploration and timely intervention will help majority of morbidity.

\section{REFERENCES}

[1] Holevar M, Ebert J, Luchette F et al. Practice Management Guidelines For The Management Of Genitourinary Trauma. The EAST Practice Management Guidelines Work Group;2004.

[2] Wein AJ, Kavoussi LR, Novick AC, Partin A, Craig P, Simpson DA. Campbell-Walsh Urology 10th edition. Surgical Anatomy of the Retroperitoneum, Adrenals, Kidneys and Ureters.Vol 1; p-20-21.

[3] Velmahos GC, Degiannis E. The management of urinary tract injuries after gunshot wounds of the anterior and posterior abdomen. Injury. 1997; 28(8):535-38.

[4] Peterson NE, Kiracofe LH. Renal trauma. when to operate. Urology. 1974; 3(5):537-43.

[5] Eastham JA, Wilson TG, Ahlering TE. Urological evaluation and management of renal proximity stab wounds. J Urol. 1993; 150(6):1771-73.

[6] Atala A, Miller FB, Richardson JD, Bauer B, Harty J, Amin M. Preliminary vascularcontrol for renal trauma. Surg Gynecol Obstet. 1991; 173:386-90.

\section{AUTHOR(S):}

1. Dr. Vinayak Gorakhnath Wagaskar

2. Dr. Vidyasagar Hansraj Baheti

3. Dr. Ajaykumar R Gajengi

4. Dr. Sujata Kiran Patwardhan

\section{PARTICULARS OF CONTRIBUTORS:}

1. Senior Resident, Deptartment of Urology, Seth G.S.M.C. and King's Edward Memorial Hospital, Mumbai, India.

2. Senior Resident, Deptartment of Urology, Seth G.S.M.C. and King's Edward Memorial Hospital, Mumbai, India.

3. Senior Resident, Deptartment of Urology, Seth G.S.M.C. and King's Edward Memorial Hospital, Mumbai, India.
4. Professor and Head, Deptartment of Urology, Seth G.S.M.C. and King's Edward Memorial Hospital, Mumbai, India.

\section{NAME, ADDRESS, E-MAIL ID OF THE} CORRESPONDING AUTHOR:

Dr. Vinayak Gorakhnath Wagaskar,

$8^{\text {th }}$ Floor, Deptartment of Urology, New Building, SGSMC and KEM Hospital Campus, Parel, Mumbai-400012, India. E-mail: vinayakwagaskar99@gmail.com

FINANCIAL OR OTHER COMPETING INTERESTS: None.

Date of Publishing: Jan 05, 2016 